\title{
Feeling (un)welcome in Switzerland: The perception of commercial hospitality by domestic and international tourists
}

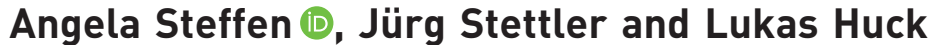 \\ Lucerne School of Business, Institute of Tourism, Lucerne, Switzerland
}

\begin{abstract}
Hospitality has been identified as one of the vital enhancing services of tourism organizations. However, insights about how tourists perceive the hospitality of touristic service providers and how these perceptions vary between guests of different origins are still scarce. Using the case of Switzerland, we conducted a survey of 600 tourists to investigate the different perceptions of hospitality by domestic and international guests in touristic service encounters. The results confirm the idea that domestic tourists are more demanding and less satisfied with the hospitality of touristic service providers than international guests. The regression analyses further indicate that tourists' gender and age influence their hospitality perceptions. Importanceperformance analyses on single dimensions of the hospitality concept suggest that touristic service providers' professional expertise is a key area in which to improve the hospitality perceptions of both domestic and international tourists.
\end{abstract}

\section{Keywords}

Hospitality, domestic tourists, importance-performance analysis, Switzerland, service quality

\section{Introduction}

Hospitable hosting behavior of touristic service providers (here referred to as commercial hospitality) has become an indispensable, distinguishing feature in service marketing. Commercial hospitality allows touristic service providers to add value to their core offerings and create memorable experiences (Pizam and Shani, 2009). This emotional dimension of the guest-host relationship, which goes beyond the paid value of services, is important to build customer loyalty and create competitive advantages (Lashley, 2008).

Recent research has increasingly explored the meaning of hospitality and investigated the attributes that guests associate with the hospitality concept (e.g., Brotherton, 2005; Nameghi and Ariffin, 2013; Pijls et al., 2017; Stettler et al., 2020; Tasci and Semrad, 2016). However, there is still a limited understanding of the dimensions of commercial hospitality that are the most important for guests and how hospitality experiences can be positively influenced in practice (Ariffin and Maghzi, 2012; Brotherton and Wood, 2008; Lashley, 2015; Lynch et al., 2011;
Ottenbacher et al., 2009; Tasci and Semrad, 2016). Outside of the hospitality context, the existing evidence suggests that domestic and international tourists have different expectations and demands on service quality in various settings (Weiermair, 2000; Yuksel, 2004). While previous studies explored the effects of nationality on tourist behavior (e.g., Pizam and Sussmann, 1995), the role of tourists' origin in hospitality perceptions is still largely unknown. Considering that domestic tourism is a key driver of the tourism sector globally (World Travel \& Tourism Council, 2018), a better understanding of domestic versus international tourists' requirements for commercial hospitality is essential to further define and apply the concept in practice.

\section{Corresponding author:}

Angela Steffen, Lucerne School of Business, Institute of Tourism, Rösslimatte 48, Rösslimatte 48, CH-6005 Lucerne, 6002 Lucerne, Switzerland.

Email: angela.steffenahslu.ch 
In the present study, we investigate domestic and international tourists' perceptions of the hospitality of touristic service providers in Switzerland. Switzerland was one of the first countries to develop tourism as a major industry and has a long-established hotel sector (Tajeddini, 2010). Besides its high attraction for tourists from Germany, the United States, UK, and China, Switzerland has retained a stable market share of domestic tourists, with Swiss guests generating around $50 \%$ of the total overnight stays over the past years (Swiss Tourism Federation, 2019). Using the case of Switzerland, we address the question of how the perceived importance of commercial hospitality and the satisfaction with the hospitality of touristic service providers differ between domestic and international tourists. The results should point out how the hospitality perceptions of domestic and international tourists traveling in Switzerland may be effectively improved in practice.

Using the scale of commercial hospitality of Stettler et al. (2020), 600 tourists traveling in Switzerland were queried about the importance of different dimensions of hospitality and their satisfaction with these dimensions in touristic service encounters. After a quantitative validation of the measurement instrument, we compared the hospitality importance and satisfaction ratings of domestic and international tourists using logistic regression analyses. In contrast to the existing literature on hospitality perceptions (e.g., Ariffin and Maghzi, 2012), this allowed us to control for various tourist-related characteristics that may influence their hospitality perceptions, such as gender, age, education, and the size of their place of residence. In-depth importance-performance analyses of the individual hospitality dimensions should then reveal key areas of action.

Our results contribute to previous literature suggesting that consumers' demographic characteristics and cultural backgrounds have a significant effect on how they evaluate the quality of touristic services (Ariffin and Maghzi, 2012; Donthu and Yoo, 2016; Joppe et al., 2016; Mattila, 2016; Tsaur et al., 2008). Transferring this idea to the hospitality context, our paper provides a better understanding of the tourist segments for whom improvements in hospitality are crucial and addresses how such improvements may be effectively realized, considering the perceived importance and performance of different hospitality dimensions. The insights and methods of this study will hopefully stimulate future research.

The remainder of the paper is structured as follows. The next section provides a literature review on the meaning of hospitality, its measurement, and the role of tourist characteristics in hospitality perceptions. Then the methodology and data are illustrated.
The regression results and importance-performance analyses are presented next. The final section provides a discussion of the findings, managerial implications, and approaches for future studies.

\section{Related literature}

\section{Hospitality meaning and measurement}

The terminology to describe hospitality in the literature is ambiguous. Since the advent of commercial accommodation, the term hospitality has been associated with the hotel and tourism industry (e.g., Pfeifer, 1983; Tideman, 1983). However, the use of hospitality to describe a service cluster has been criticized by several researchers (Lashley, 2001). More recent studies rather refer to hospitality as the attitudes and behavior of service employees (Ariffin and Maghzi, 2012; Lashley, 2017; Smith, 1994; Tasci and Semrad, 2016), here labeled as commercial hospitality.

For the most part, the existing research has not focused on hospitality in a narrow sense but on service quality (Parasuraman et al., 1988). According to Romeiss-Stracke (1995), hospitality is one of several components of the quality of tourism services. Smith (1994), however, noted that hospitality and service are two distinct elements of the tourism product, whereby hospitality can be defined as the enhanced service or the style and attitude in which the service is performed. Pechlaner et al. (2017) understand hospitality as part of an encompassing quality strategy for the encounter of host and guest, which is highly influenced by an inner attitude and reciprocity.

The idea that hospitality involves emotional experiences of special interactions between the host and the guest was also supported by Pechlaner and Raich (2007). Lashley (2001: 15) noted that hospitality "require[s] the guest to feel that the host is being hospitable through feelings of generosity, a desire to please, and a genuine regard for the guest as an individual." Service providers should strive to offer memorable services by focusing on guest experiences that stimulate their senses (Hemmington, 2007). Supporting this view, Ritzer (2007) suggested that predictability and control are among the dimensions that act as barriers to hospitality and memorable service experiences. Telfer (2001) underlined that truly hospitable behavior is motivated by genuine needs to please and care for others and should not be practiced to deliberately impress the guest or for the expectation of repayment.

Brotherton (2005) and Brotherton and Wood (2008) investigated hotel guests' perceptions of the service-related and physical aspects of hospitality. Terms most often associated with hospitable service 
behavior were "welcoming", "friendly", "polite", "pleasant", and "warm". Sim et al. (2006) related hospitality to employees greeting people with courtesy, meeting customer needs, being patient, communicating well, letting customers feel important and secure, and being friendly, polite, and cheerful. In an attempt to further explore the meaning of hospitality, more recent studies have developed scales for measuring hospitable attitudes and behavior in the tourism sector (Ariffin and Maghzi, 2012; Blain and Lashley, 2017; Pijls et al., 2017; Stettler et al., 2020; Tasci and Semrad, 2016). Ariffin and Maghzi (2012), for example, proposed a 22-item scale to measure hospitable behavior in hotel services. According to their study, hospitality is concerned with personalized services and comfort for the satisfaction of customers' physiological and psychological needs. The scale developed by Blain and Lashley (2017) proposes three dimensions: the desire to put customers before oneself, to make them happy, and to make them feel special. In a more recent study, the empirical analysis of Tasci and Semrad (2016) also resulted in a three-factor scale of hospitality, differentiating between heart-warming (welcoming, courteous, respectful, and kind), heartassuring (trustworthy, honest, reliable), and heartsoothing (generous, sociable, and open) factors. Similar terms were already used by Burgess (1982: 50). The experiential dimensions of hospitality investigated by Pijls et al. (2017) contain the three factors of "inviting", "care", and "comfort". The inviting factor, which means feeling invited, experiencing openness, and experiencing freedom, has the largest predictive value for the overall hospitality experience in their analysis. For measuring tourists' hospitality perceptions in this study, we referred to the conceptual framework of commercial hospitality and the corresponding hospitality scale of Stettler et al. (2020).

\section{Framework of commercial hospitality of Stettler et al. (2020)}

The framework of Stettler et al. (2020) illustrates the factors that influence hospitality within the guest-host relationship by differentiating among three layers: general dimensions, supporting dimensions, and core dimensions of commercial hospitality (see Figure 1).

General dimensions: As mentioned by Müller and Boess (1995) and Thiem (1996), cultural identity as well as political issues and laws (e.g., employment laws) influence tourism attitudes and consciousness. Such general factors, for example, traditions or norms, are deeply rooted within the lifestyle of the host community. They influence the way hosts display hospitality as well as how guests expect and perceive hospitality in the cultural context of the destination.
Supporting dimensions: Based on the SERVQUAL concept (Parasuraman et al., 1988) and supported by the findings of Brotherton and Wood (2008), there are several, more tangible factors that can support the way in which guests perceive hospitality. These factors include, for example, guest-oriented service processes (King, 1995), cleanliness (Reid and Bojanic, 2010), or the physical environment and appearance of service employees (Parasuraman et al., 1988; Saleh and Ryan, 1992).

Core dimensions: Of particular interest for this study are the hospitality dimensions of the third layer, designated as hospitality core dimensions. The core dimensions refer to the attitudes and behaviors of service employees in tourism and therefore directly contribute to guests' hospitality experiences. In line with the SERVQUAL approach, this third layer highlights the importance of a person's behavior for the quality of a service (Parasuraman et al., 1988). A detailed description of the hospitality core dimensions is provided in supplementary Appendix A.

The framework of commercial hospitality of Stettler et al. (2020) was developed in a qualitative multi-stage approach. A literature review and three explorative qualitative studies were conducted to identify, define, and validate the hospitality core dimensions. These methodological steps are provided in more detail in supplementary Appendix B.

\section{Hospitality perceptions and tourist characteristics}

The existing literature shows that demographic consumer characteristics such as age, gender, ethnicity, education, and income have a significant effect on the quality expectations for professional services (e.g., Bishop Gagliano and Hathcote, 1994; Juwaheer, 2007; Webster, 1989). Female guests, for example, were found to have higher expectations of hotel service quality than male guests (Juwaheer, 2007) and tend to be more influenced by relational aspects of service encounters (e.g., polite and helpful contact employees) (Iacobucci and Ostrom, 1993). On the other hand, functional service quality including service efficiency and accuracy, has greater predictive power for males (Sánchez-Hernández et al., 2010). In line with this notion, women were found to be less satisfied than men with negative emotional displays in mundane service situations (Mattila et al., 2003). With regard to age, previous studies have shown that mature travelers are more discerning of the quality of service interactions and place higher importance on the attitudes and behaviors of service staff (Callan and Bowman, 2000). Differences among guests of different age groups were also identified for 


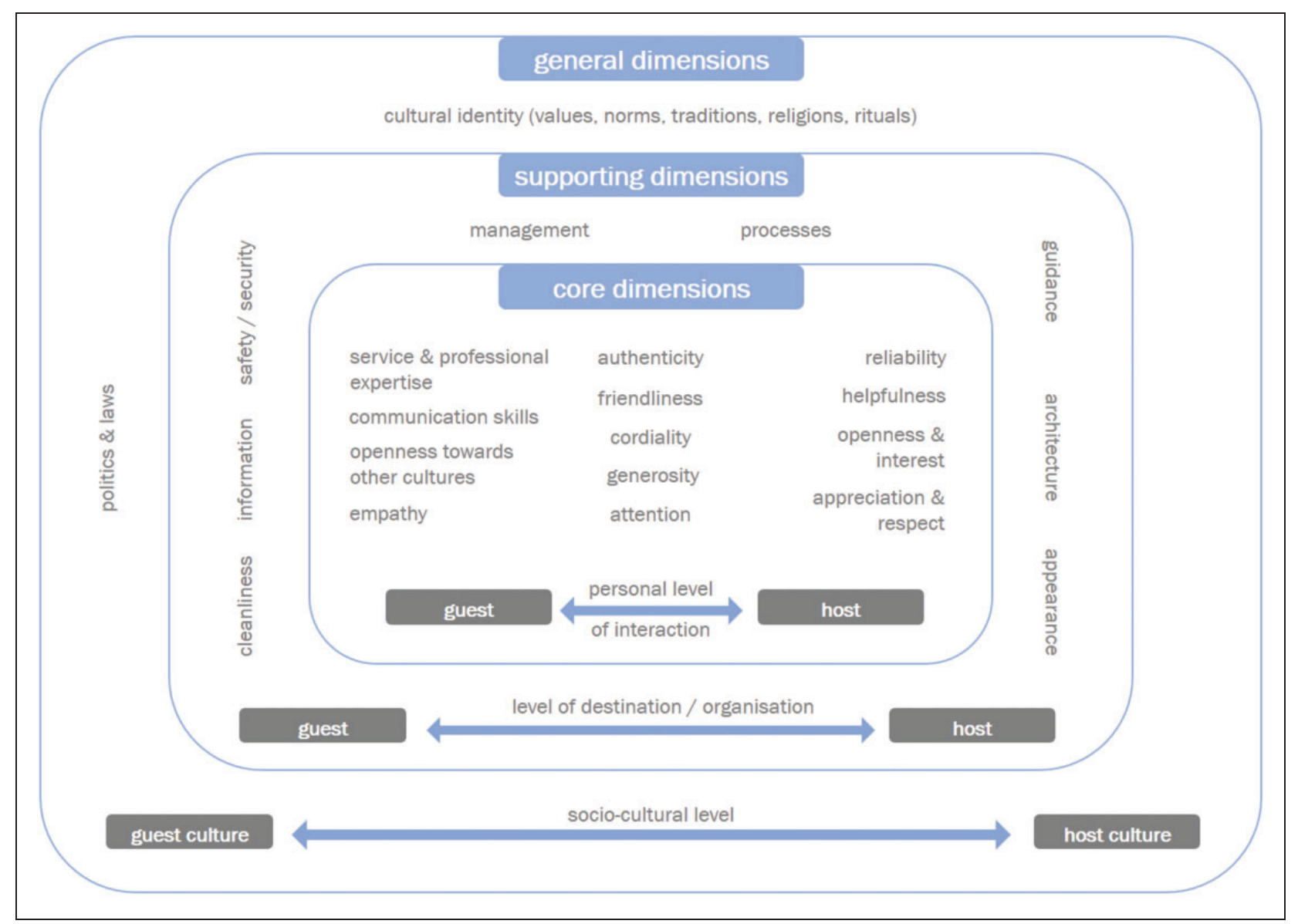

Figure 1. Conceptual framework of commercial hospitality (Stettler et al., 2020).

the reliability dimension of service quality (Juwaheer, 2007; Tabassum et al., 2012). In a tourism context, previous studies focused on the influence of cultural backgrounds on service evaluations. Using the SERVQUAL approach, Tsaur et al. (2008), for example, demonstrated that tourists from English-heritage cultures tend to perceive better service quality than their Asian and other European counterparts in the areas of tangibles, reliability, and empathy. This supports earlier findings indicating that individual tourists (such as English-heritage and European guests), due to their drive and self-responsibility ethic, demand a high level of service quality and expect the service provider to care for them efficiently (Donthu and Yoo, 2016; Mattila, 2016). The importance of cultural differences in service perceptions has also been highlighted by Torres et al. (2014), showing that, besides some universal service elements, guests from different cultures can be delighted by different services and amenities. American guests, for example, seem to emphasize the value aspect of the service experience (e.g., complimentary amenities or upgrades), while guests from Northern Europe place greater emphasis on intangible service aspects such as friendliness, professionalism, and problem-solving. Joppe et al. (2016) confirmed that visitors from different countries of origin show different importance and satisfaction levels for the attributes of a tourism destination. In particular, tourists from overseas are shown to be more satisfied with the hospitality of local people than domestic visitors are, while this attribute was of similar importance for all tourists. With a closer link to commercial hospitality, Ariffin and Maghzi (2012) found that domestic tourists place higher importance on hospitality in hotel services compared to international tourists. In contrast to this paper, however, their study does not address tourists' satisfaction with hospitality and is confined to guests of fourand five-star hotels. Weiermair (2000) suggested that the closer tourists' own cultures are located to an experienced cross-cultural service encounter in a destination, the more critical they are in terms of perceiving service quality and experiencing satisfaction. In contrast, the greater a customer's cultural distance, the less demanding and the more tolerant he or she tends to be when evaluating service quality. We thus 
hypothesize that domestic tourists place a higher importance on commercial hospitality and are less satisfied with their hospitality experiences in touristic service encounters. We further presume that domestic and international tourists have different needs and expectations regarding the various dimensions that are associated with hospitality, such as service providers' friendliness, openness, or generosity. Weiermair and Fuchs (1999) showed that the influence of culture on service quality perception varies across the examined service quality dimensions. We thus expect that the importance and satisfaction ratings of domestic and international tourists also differ with regard to the individual dimensions of the hospitality concept (see Section Framework of commercial hospitality of Stettler et al. (2020)).

\section{Methodology}

\section{Measurement scale}

For measuring tourists' hospitality perceptions, we used the scale of commercial hospitality developed and pre-tested by Stettler et al. (2020). An interdisciplinary research team, consisting of experts from tourism, methodology, and communication, translated the hospitality core dimensions of the conceptual framework (see Figure 1) into scalable items. The dimension of cordiality, for example, was described as "Employees working in tourism enterprises showed sincere and positive emotions as well as sympathy towards me." The operationalization of each dimension is provided in Table 1.

Participants were asked to indicate how important they perceived each dimension to be (measuring hospitality importance) and how satisfied they were with each dimension (measuring hospitality satisfaction) in a tourism service context. Respondents' importance and satisfaction ratings were measured on a fivepoint Likert scale, ranging from 1 (very unsatisfied/ completely unimportant) to 5 (very satisfied/very important). To ensure that the linguistic meaning is cohesive and consistent, the questionnaire was checked and revised in multiple rounds, involving international research partners. The final German questionnaire was translated into English, then retranslated back into German by professional translators, to manage the validity of the two versions. The translation and retranslation were content validated by native Englishand German-speaking project partners.

To further examine the readability and comprehensibility of the questionnaire and to check for wording, ambiguity, and order effects, the questionnaire was pre-tested in English and German. A total of 60 pretest participants were randomly selected at tourism hotspots and hotels in Central Switzerland. The pretest resulted in no major revision of the questionnaire; however, a decision was made to use static matrixboxes instead of sliders. Also, the option "no answer" was marked more clearly.

The final questionnaire contained the following three sections: (1) questions about participants' stays and use of local leisure offers, (2) their perceived importance and satisfaction regarding the 13 hospitality core dimensions, and (3) common demographic variables (see Stettler et al., 2020).

\section{Data collection and sample}

The survey was administered at tourism hotspots and hotels in Central Switzerland. To increase the number of potential participants, the respondents could complete the questionnaire on a tablet PC (527 observations) or in a paper-and-pencil form (74 observations). ${ }^{1}$ In addition, depending on the data collection site they could choose to complete the questionnaire in English or the local language (German).

Data collectors at all sites were college students, who assisted researchers across the project. As in prior studies on tourism service assessments (e.g., Ahmad et al., 2008), the sample was selected using a judgmental sampling technique. Accordingly, respondents were selected on the basis of the researchers' judgment about which ones would be the most useful or representative (Babbie, 2013). Completing the questionnaire took an average of seven minutes.

On the basis of a power analysis, we aimed at 400 completed questionnaires consisting of 200 domestic and 200 international tourists. All questionnaires with more than $10 \%$ of items unanswered were excluded from the analysis. To keep the focus on commercial hospitality, we also dropped participants who did not stay in a commercial accommodation at the time of the survey. This resulted in a total number of 600 participants, 233 domestic and 367 international.

Table 2 provides the characteristics of the sample as a whole and for the domestic and international tourists separately. The largest proportion of the international participants came from the United States $(18.5 \%)$, Germany (15\%), China (7.9\%), and the United Kingdom (6.8\%), mirroring the most important countries of origin in the Swiss accommodation statistics (Swiss Tourism Federation, 2019). ${ }^{2}$

The majority of participants were international, female tourists with a university degree. The mean age of the respondents was 38.2 years ( 40.3 years for the domestic and 36.9 years for the international tourists). We also measured the size of the participants' places of residence by asking them to select one of four 
Table 1. Operationalization of the hospitality core dimensions.

\begin{tabular}{|c|c|}
\hline Core dimension & Item in the questionnaire \\
\hline Friendliness & $\begin{array}{l}\text { Employees working in tourism enterprises provided me with a friendly welcome, } \\
\text { especially upon arrival. }\end{array}$ \\
\hline $\begin{array}{l}\text { Service and professional } \\
\text { expertise }\end{array}$ & $\begin{array}{l}\text { Employees working in tourism enterprises possessed the knowledge to answer my } \\
\text { questions. }\end{array}$ \\
\hline $\begin{array}{l}\text { Openness toward } \\
\text { other cultures }\end{array}$ & $\begin{array}{l}\text { Employees working in tourism enterprises knew how to respond to the specific needs of } \\
\text { guests from different cultures. }\end{array}$ \\
\hline Empathy & Employees working in tourism enterprises anticipated my needs. \\
\hline Authenticity & $\begin{array}{l}\text { Employees working in tourism enterprises treated me with genuine and sincere } \\
\text { behavior. }\end{array}$ \\
\hline Communication skills & $\begin{array}{l}\text { Employees working in tourism enterprises communicated with me adequately for the } \\
\text { specific situation. }\end{array}$ \\
\hline Cordiality & $\begin{array}{l}\text { Employees working in tourism enterprises showed sincere and positive emotions as } \\
\text { well as sympathy towards me. }\end{array}$ \\
\hline $\begin{array}{l}\text { Appreciation and } \\
\text { respect }\end{array}$ & $\begin{array}{l}\text { Employees working in tourism enterprises provided services with respect and a sense } \\
\text { of tact. }\end{array}$ \\
\hline Attention & $\begin{array}{l}\text { Employees working in tourism enterprises provided me with individual and personal } \\
\text { attention. }\end{array}$ \\
\hline Reliability & $\begin{array}{l}\text { Employees working in tourism enterprises performed services that were promised to } \\
\text { me independently and accurately. }\end{array}$ \\
\hline Helpfulness & $\begin{array}{l}\text { Employees working in tourism enterprises helped me with problems or questions, even } \\
\text { when the problem was not their responsibility. }\end{array}$ \\
\hline Interest and openness & Employees working in tourism enterprises treated me without prejudice. \\
\hline Generosity & $\begin{array}{l}\text { Employees working in tourism enterprises handled my complaints and claims with the } \\
\text { necessary generosity. }\end{array}$ \\
\hline
\end{tabular}

Table 2. Sample characteristics.

\begin{tabular}{|c|c|c|c|c|}
\hline & $\begin{array}{l}\text { Total } \\
\mathrm{N}=600\end{array}$ & $\begin{array}{l}\text { Domestic } \\
\mathrm{N}=233\end{array}$ & $\begin{array}{l}\text { International } \\
\mathrm{N}=367\end{array}$ & $p$-value \\
\hline \multicolumn{5}{|l|}{ Gender } \\
\hline Female & 0.60 & 0.60 & 0.60 & 0.923 \\
\hline Male & 0.40 & 0.40 & 0.40 & 0.923 \\
\hline \multicolumn{5}{|l|}{ Age } \\
\hline$<=24$ & 0.14 & 0.09 & 0.18 & 0.003 \\
\hline $25-44$ & 0.55 & 0.56 & 0.54 & 0.659 \\
\hline $45-60$ & 0.22 & 0.25 & 0.20 & 0.149 \\
\hline$>60$ & 0.09 & 0.1 & 0.08 & 0.377 \\
\hline \multicolumn{5}{|l|}{ Education } \\
\hline Secondary (compulsory) & 0.05 & 0.03 & 0.06 & 0.096 \\
\hline Post-secondary vocational & 0.14 & 0.29 & 0.04 & 0.000 \\
\hline Post-secondary non-tertiary & 0.16 & 0.29 & 0.08 & 0.000 \\
\hline University degree & 0.65 & 0.39 & 0.82 & 0.000 \\
\hline \multicolumn{5}{|l|}{ Place of residence } \\
\hline City & 0.5 & 0.23 & 0.67 & 0.000 \\
\hline Medium town & 0.16 & 0.14 & 0.18 & 0.266 \\
\hline Small town & 0.14 & 0.19 & 0.10 & 0.002 \\
\hline Village & 0.2 & 0.44 & 0.05 & 0.000 \\
\hline \multicolumn{5}{|l|}{ Type of accommodation } \\
\hline Hotel & 0.68 & 0.66 & 0.69 & 0.341 \\
\hline Other & 0.32 & 0.34 & 0.31 & 0.341 \\
\hline
\end{tabular}

Note: The table reports percentage frequencies for the full sample and for the domestic and international tourists individually. The $p$-value in the last column was obtained from a $\chi^{2}$ test across domestic and international tourists. 
categories (see Table 2), and their type of accommodation at the time of the survey, that is, whether they stayed in a hotel or in another (commercial) accommodation such as a youth hostel, holiday flat, or B\&B. The $\chi^{2}$ test in the last column indicates significant differences between the domestic and international participants in terms of their age structure, education levels, and places of residence. These differences are controlled for in the regression analyses.

\section{Quantitative validation of the measurement scale}

Before forming indices for hospitality importance and hospitality satisfaction, we quantitatively validated the hospitality scale of Stettler et al. (2020) using confirmatory factor analysis (CFA). The results of the single-factor structural equation models for tourists' satisfaction and importance ratings on each hospitality core dimension are provided in supplementary Appendix C. For the evaluation of the models, we followed a multi-criteria approach, as suggested by $\mathrm{Hu}$ and Bentler (1999). The maximum likelihood $\chi^{2}$ statistic, comparative fit index (CFI), TuckerLewis index (TLI), standardized root mean squared residual (SRMR), and other indices suggested that the overall fit of the initial models might benefit from modification. Examination of standardized residual covariances signaled the need to remove the item friendliness due to its high residual covariance with other items, particularly service and professional expertise. Although friendliness, from a conceptual point of view, seems to be very closely related to the hospitality construct, it is plausible to consider friendliness as an antecedent of the perception of other experiential dimensions of hospitality rather than a dimension of its own. Removing friendliness from the hospitality importance and satisfaction scales resulted in an improved model fit: $\chi^{2}=191.8, \quad \mathrm{CFI}=0.939$, $\mathrm{TLI}=0.925$, and $\mathrm{SRMR}=0.044$ for the modified hospitality satisfaction scale (vs. $\chi^{2}=252.6$, $\mathrm{CFI}=0.920, \mathrm{TLI}=0.904$, and $\mathrm{SRMR}=0.053$ for the initial scale) and $\chi^{2}=135.3, \quad \mathrm{CFI}=0.944$, $\mathrm{TLI}=0.932$, and $\mathrm{SRMR}=0.041$ for the modified hospitality importance scale (vs. $\chi^{2}=191.9$, $\mathrm{CFI}=0.919, \mathrm{TLI}=0.903$, and $\mathrm{SRMR}=0.047$ for the initial scale). ${ }^{3}$ Both modified scales met the criteria of $\mathrm{CFI}>0.90$ and $\mathrm{SRMR}<0.08$ in the CFA (see Marsh et al., 2004; Matsunaga, 2010). The loading coefficients of the remaining 12 items were all significant, ranging from 0.54 to 0.79 (hospitality satisfaction) and from 0.49 to 0.68 (hospitality importance). ${ }^{4}$ Principal component analyses of the hospitality importance and hospitality satisfaction items support the unidimensionality of both constructs (see Figures 5 and 6 in supplementary Appendix C).

We further used Cronbach's alpha to test the internal reliability of the scales (see Churchill, 1979). After removing the item friendliness, we observed $\alpha=0.85$ for hospitality importance and $\alpha=0.91$ for hospitality satisfaction, indicating a high internal reliability of both scales (Nunnally and Bernstein, 2008). We further observed an average inter-item correlation of 0.46 for the hospitality satisfaction scale and 0.32 for the hospitality importance scale. Clark and Watson (1995) recommended a mean inter-item correlation within the range of 0.15 to 0.20 for scales that measure broad characteristics and between 0.40 to 0.50 for those measuring narrower ones (also see Cristobal et al., 2007; Kim and Stoel, 2004 ). This is consistent with our data. The remaining 12 items had relatively similar item-to-scale correlations and all fit the monotonicity assumption of the summated rating model. The detailed inter-item correlations are also provided in supplementary Appendix C.

\section{Data analysis}

The differences in hospitality perceptions between domestic and international tourists were analyzed in an ordered logistic regression model (see McCullagh, 1980; Murad et al., 2003). ${ }^{5}$ Participants' mean importance or satisfaction rating of commercial hospitality (modified scales with 12 items each) served as dependent variables. The details of the regression models and variables are provided in Sections Importance of commercial hospitality and Satisfaction with commercial hospitality.

To investigate the differences in hospitality perceptions in more detail, we conducted WilcoxonMann-Whitney tests for the importance and satisfaction ratings of domestic and international tourists for the individual hospitality core dimensions. The joint consideration of the importance and satisfaction ratings should then reveal key areas of action. For this purpose, we plotted the evaluations of the hospitality core dimensions in two importance-performance analyses (IPAs) for domestic and international tourists (see Martilla and James, 1977). The use of IPA is welldocumented in the tourism literature and has been found to be a conceptually valid and powerful technique for evaluating service attributes and developing marketing strategies as, for example, in tourism destinations (Hudson and Shephard, 1998; Joppe et al., 2016; Kreß et al., 2018). The main advantage of IPA lies in its simplicity in projecting results and pointing out critical areas of action (Azzopardi and Nash, 2013; Oh, 2001). Figure 2 provides a visual display of the strategic interpretation of an IPA grid. 


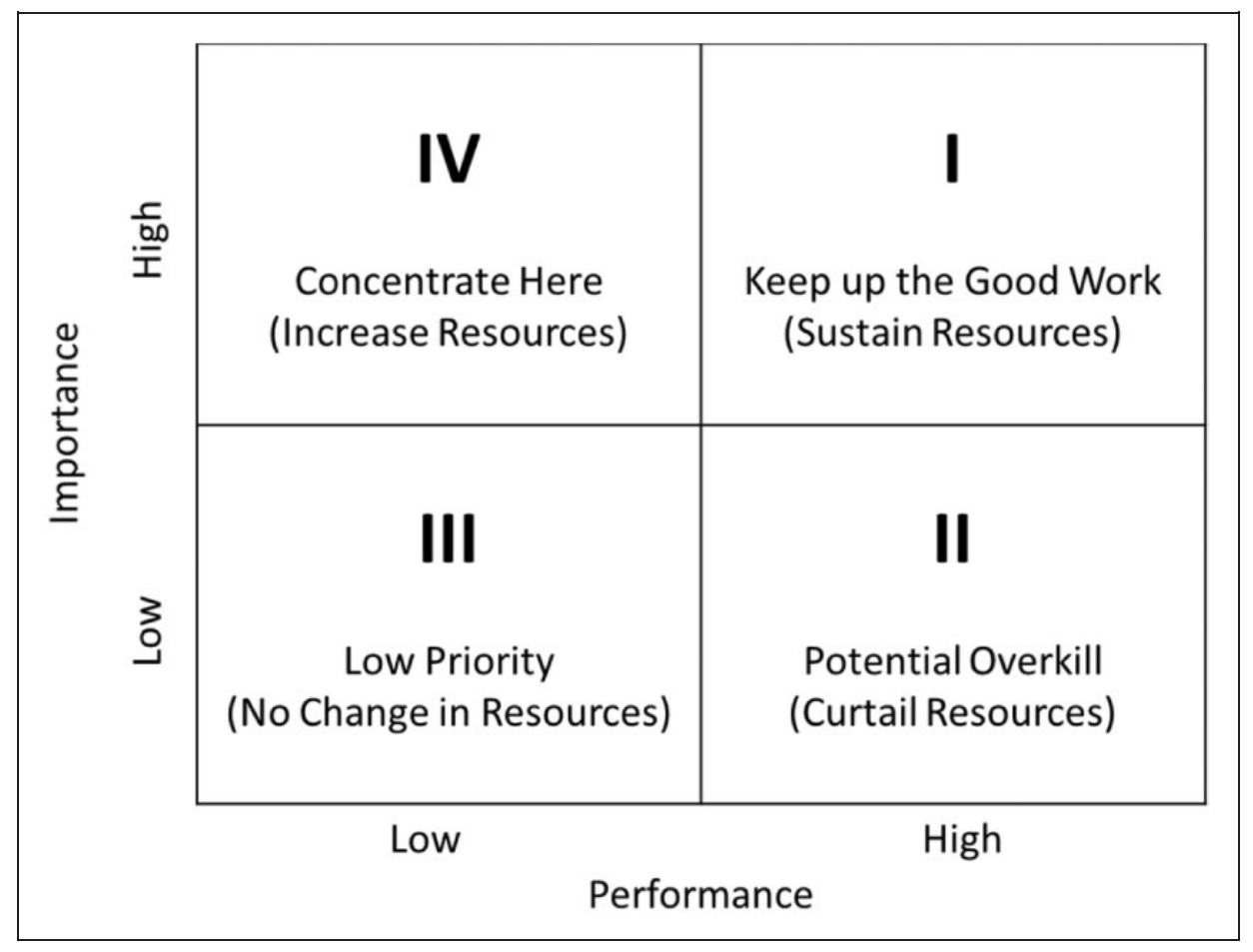

Figure 2. The IPA framework (Martilla and James, 1977).

\section{Results}

\section{Importance of commercial hospitality}

We first investigate potential differences between domestic and international tourists with regard to the importance of commercial hospitality. Table 3provides the results of an ordered logistic regression analysis, where the dependent variable is the mean hospitality importance rating per participant. Our main independent variable of interest is the participants' origin, that is, whether they are domestic or international tourists. In specification 2 of the model, we control for various tourist-related characteristics which presumably influence the perceived importance of the hospitality core dimensions. These control variables are gender (a dummy variable with the value 1 for males and 0 for females), age (in years), education level (i.e., participants' highest stage of education), place of residence (i.e., whether the participants describe their hometown as a village, small town, medium-sized town, or city), and type of accommodation (i.e., whether the participants stayed in a hotel (0) or another type of accommodation (1) at the time of the survey).

The coefficients in Table 3 are written as odds ratios-that is, the increase in the odds of rating the hospitality importance higher vs. the odds of rating the hospitality importance equal or lower for a one-unit change in the predictor variable. An odds ratio greater than 1 indicates a positive association between the perceived importance of hospitality and the predictor variable, while an odds ratio lower than 1 indicates a negative association between the perceived importance of hospitality and the predictor variable.

Without any control variables, specification 1 in Table 3 suggests that international tourists rate commercial hospitality, on average, as more important than domestic tourists do. Specification 2, however, reveals that this effect is only marginally significant when other tourist-related characteristics are taken into account. At a significance level of 0.05 , we reject the hypothesis that domestic tourists who travel in Switzerland give more importance to service providers' hospitality than international tourists do. Importance ratings rather seem to be related to tourists' gender and age. In fact, male tourists consider commercial hospitality as significantly less important than females do, and the importance ratings increase linearly with the tourists' age. The level of education and the place of origin do not have a significant effect. Although not significant, hospitality also seems to be less of a concern for tourists who stay in accommodations other than hotels (e.g., youth hostel, holiday flat, $\mathrm{B} \& \mathrm{~B}$, etc.). This is in line with existing evidence suggesting a negative relationship between the importance of different hospitality dimensions and the chosen hotel category (Ariffin and Maghzi, 2012). 
Table 3. Ordered logistic regression: Importance of commercial hospitality.

\begin{tabular}{|c|c|c|}
\hline & $\begin{array}{l}\text { Odds ratios } \\
\text { (1) }\end{array}$ & $\begin{array}{l}\text { Odds ratios } \\
\text { (2) }\end{array}$ \\
\hline International (vs. Domestic) & $\begin{array}{l}1.444^{* *} \\
(0.209)\end{array}$ & $\begin{array}{l}1.422 * \\
(0.278)\end{array}$ \\
\hline Male (vs. Female) & & $\begin{array}{l}0.568 * * * \\
(0.090)\end{array}$ \\
\hline Age (in years) & & $\begin{array}{l}1.011 * * \\
(0.006)\end{array}$ \\
\hline Vocational (vs. Secondary) & & $\begin{array}{l}0.981 \\
(0.459)\end{array}$ \\
\hline Non-tertiary (vs. Secondary) & & $\begin{array}{l}1.100 \\
(0.506)\end{array}$ \\
\hline University degree (vs. Secondary) & & $\begin{array}{l}1.090 \\
(0.450)\end{array}$ \\
\hline Medium town (vs. City) & & $\begin{array}{l}0.830 \\
(0.184)\end{array}$ \\
\hline Small town (vs. City) & & $\begin{array}{l}0.738 \\
(0.177)\end{array}$ \\
\hline Village (vs. City) & & $\begin{array}{l}0.971 \\
(0.233)\end{array}$ \\
\hline Other (vs. Hotel) & & $\begin{array}{l}0.807 \\
(0.135)\end{array}$ \\
\hline Observations & 597 & 524 \\
\hline Model chi-square & 6.472 & 25.397 \\
\hline Log likelihood & -2059.728 & -1784.631 \\
\hline McFadden's pseudo R-squared & 0.002 & 0.007 \\
\hline
\end{tabular}

Note: Specifications 1 and 2 present the results of an ordered logistic regression with exponentiated coefficients and standard errors in parentheses. The dependent variable is the mean importance rating of the hospitality core attributes per participant. In addition to the tourists' origin in specification 1, specification 2 includes control variables for tourists' age, education, place of residence and type of accommodation. Three observations in specification 1 and 76 observations in specification 2 were dropped due to incomplete answers. ${ }^{*} p$ $<0.10,{ }^{* *} p<0.05,{ }^{* *} p<0.01$.

\section{Satisfaction with commercial hospitality}

We now investigate potential differences between domestic and international tourists' satisfaction with the hospitality of touristic service providers. For this purpose, we have run the same logistic regression analysis as in Section Importance of commercial hospitality, with participants' mean satisfaction ratings of the hospitality core dimensions as the dependent variable. As in the previous model, we control for tourists' gender, age, level of education, place of residence, and type of accommodation (see Section Importance of commercial hospitality). To account for a potential relationship between the hospitality importance and satisfaction ratings, we also include participants' hospitality importance ratings as a continuous control variable in specification 3 of Table 4 . Table 4 provides the regression results.

Specification 1 indicates that international tourists are significantly more satisfied with the hospitality of touristic service providers than are domestic tourists. This effect increases when adding the tourist-related control variables in specification 2 of the model.
Specification 2 also shows that tourists' satisfaction with commercial hospitality rises with their age. As indicated in specification 3, controlling for hospitality importance ratings does not change the differences in the satisfaction of domestic and international tourists. Interestingly, tourists' perceived importance of commercial hospitality is positively related to their satisfaction. This is in line with earlier studies in the tourism context showing that important attributes are typically evaluated more favorably than attributes that are less important (Hollenhorst et al., 1992; Oh, 2001). Specification 3 further indicates that males are significantly more satisfied with the hospitality of local service providers than females are.

Overall, the results suggest that domestic tourists traveling in Switzerland are significantly less satisfied with the hospitality of touristic service providers, although they perceive hospitality as similarly important (see Section Importance of commercial hospitality). We explain this finding by the idea that international tourists do not have a specific standard to evaluate their hospitality experience in the 
Table 4. Ordered logistic regression: Satisfaction with commercial hospitality.

\begin{tabular}{|c|c|c|c|}
\hline & $\begin{array}{l}\text { Odds ratios } \\
\text { (1) }\end{array}$ & $\begin{array}{l}\text { Odds ratios } \\
\text { (2) }\end{array}$ & $\begin{array}{l}\text { Odds ratios } \\
\text { (3) }\end{array}$ \\
\hline International (vs. Domestic) & $\begin{array}{l}1.377^{* *} \\
(0.200)\end{array}$ & $\begin{array}{l}1.721 * * * \\
(0.343)\end{array}$ & $\begin{array}{l}1.688 * * * \\
(0.339)\end{array}$ \\
\hline Male (vs. Female) & & $\begin{array}{l}1.047 \\
(0.164)\end{array}$ & $\begin{array}{l}1.451^{* *} \\
(0.230)\end{array}$ \\
\hline Age (in years) & & $\begin{array}{l}1.020 * * * \\
(0.006)\end{array}$ & $\begin{array}{l}1.015^{* * *} \\
(0.006)\end{array}$ \\
\hline Vocational (vs. Secondary) & & $\begin{array}{l}0.815 \\
(0.362)\end{array}$ & $\begin{array}{l}0.921 \\
(0.423)\end{array}$ \\
\hline Non-tertiary (vs. Secondary) & & $\begin{array}{l}0.777 \\
(0.339)\end{array}$ & $\begin{array}{l}0.731 \\
(0.327)\end{array}$ \\
\hline University degree (vs. Secondary) & & $\begin{array}{l}0.792 \\
(0.308)\end{array}$ & $\begin{array}{l}0.684 \\
(0.274)\end{array}$ \\
\hline Medium town (vs. City) & & $\begin{array}{l}0.893 \\
(0.196)\end{array}$ & $\begin{array}{l}0.979 \\
(0.214)\end{array}$ \\
\hline Small town (vs. City) & & $\begin{array}{l}1.169 \\
(0.285)\end{array}$ & $\begin{array}{l}1.292 \\
(0.315)\end{array}$ \\
\hline Village (vs. City) & & $\begin{array}{l}1.445 \\
(0.363)\end{array}$ & $\begin{array}{l}1.432 \\
(0.369)\end{array}$ \\
\hline Other (vs. Hotel) & & $\begin{array}{l}0.804 \\
(0.134)\end{array}$ & $\begin{array}{l}0.846 \\
(0.143)\end{array}$ \\
\hline Hospitality importance & & & $\begin{array}{l}9.388 * * * \\
(1.842)\end{array}$ \\
\hline Observations & 595 & 523 & 523 \\
\hline Model chi-square & 4.862 & 23.958 & 154.599 \\
\hline Log likelihood & -2178.973 & -1889.563 & -1824.243 \\
\hline McFadden's pseudo R-square & 0.001 & 0.006 & 0.041 \\
\hline
\end{tabular}

Note: Specifications 1-3 present the results of an ordered logistic regression with exponentiated coefficients and standard errors in parentheses. The dependent variable is the mean satisfaction rating of the hospitality core attributes per participant. In addition to the tourists' origin in specification 1, specification 2 includes control variables for tourists' age, education, place of residence, and type of accommodation. Specification 3 further includes the mean importance rating of the hospitality core attributes. Five observations in specification 1 and 77 observations in specifications 2 and 3 were dropped due to incomplete satisfaction ratings. ${ }^{* *} p<0.05,{ }^{* * *} p<0.01$.

commercial context. Domestic tourists, on the other hand, base their expectation on the standard of local culture, which they are already familiar with (Ariffin et al., 2011). A similar pattern can be observed for female tourists, who perceive hospitality to be more important than their male counterparts do, but who are less satisfied with their hospitality experiences in a commercial tourism context. ${ }^{6}$ Domestic tourists and female guests may thus be considered as critical target groups for whom improvements in hospitality by touristic service providers seem to be crucial. Older tourists place more importance on hospitality but are also significantly more satisfied than younger guests.

The results of the regression analyses are robust when using the initial 13-item hospitality satisfaction and hospitality importance scales of Stettler et al. (2020). Estimating the effects in a generalized structural equation model with hospitality satisfaction and hospitality importance as latent constructs also leads to very similar results (see supplementary Appendix D).

\section{Importance and satisfaction ratings of hospitality core dimensions}

Given the significant differences in the hospitality perceptions of domestic and international tourists traveling in Switzerland, we aim to investigate the origin of these differences by analyzing the individual hospitality core dimensions in more detail. Tables 5 and 6 provide the mean importance and satisfaction ratings for the hospitality core dimensions where the Wilcoxon-Mann-Whitney tests indicate significant differences between domestic and international tourists.

The results reveal that domestic and international tourists show different priorities and different satisfaction ratings with regard to various dimensions of the hospitality concept. Domestic travelers, for example, tend to have a more critical perception of service providers' openness toward other cultures, their generosity, and their communication skills. However, the majority 
Table 5. Importance of hospitality core dimensions.

\begin{tabular}{|c|c|c|c|c|c|c|}
\hline & \multicolumn{2}{|c|}{ Domestic } & \multicolumn{2}{|c|}{ International } & \multirow[b]{2}{*}{$\Delta$} & \multirow[b]{2}{*}{$p$} \\
\hline & mean & SD & mean & SD & & \\
\hline Cordiality & 4.56 & 0.69 & 4.41 & 0.8 & 0.15 & 0.018 \\
\hline Authenticity & 4.53 & 0.75 & 4.4 & 0.79 & 0.13 & 0.022 \\
\hline Reliability & 4.61 & 0.63 & 4.5 & 0.7 & 0.11 & 0.053 \\
\hline Empathy & 4.22 & 0.79 & 4.33 & 0.87 & -0.11 & 0.015 \\
\hline Interest and openness & 4.26 & 0.85 & 4.44 & 0.76 & -0.18 & 0.010 \\
\hline Communication skills & 4.31 & 0.8 & 4.53 & 0.72 & -0.22 & 0.000 \\
\hline Openness toward other cultures & 3.77 & 1.01 & 4.32 & 0.91 & -0.55 & 0.000 \\
\hline
\end{tabular}

Note: The table reports the mean and standard deviation (SD) of the importance ratings of the hospitality core dimensions with significant differences between domestic and international tourists. The $p$-value in the last column was obtained from a Wilcoxon-MannWhitney test.

Table 6. Satisfaction with hospitality core dimensions.

\begin{tabular}{|c|c|c|c|c|c|c|}
\hline & \multicolumn{2}{|c|}{ Domestic } & \multicolumn{2}{|c|}{ International } & \multirow[b]{2}{*}{$\Delta$} & \multirow[b]{2}{*}{$p$} \\
\hline & mean & SD & mean & SD & & \\
\hline Openness toward other cultures & 4.03 & 0.96 & 4.34 & 0.91 & -0.31 & 0.000 \\
\hline Generosity & 4.09 & 0.87 & 4.28 & 0.83 & -0.19 & 0.016 \\
\hline Communication skills & 4.32 & 0.86 & 4.48 & 0.76 & -0.16 & 0.014 \\
\hline Attention & 4.23 & 0.87 & 4.34 & 0.85 & -0.11 & 0.082 \\
\hline Interest and openness & 4.25 & 0.76 & 4.35 & 0.87 & -0.10 & 0.025 \\
\hline
\end{tabular}

Note: The table reports the mean and standard deviation (SD) of the satisfaction ratings of the hospitality core dimensions with significant differences between domestic and international tourists. The $p$-value in the last column was obtained from a Wilcoxon-MannWhitney test.

of these core dimensions also seem to be of minor importance for domestic tourists.

To identify the strategic hospitality core dimensions that should receive particular attention by touristic service providers in Switzerland, we jointly consider the importance and satisfaction ratings and conduct two IPAs. The crosshair points of the IPA grids are defined by the mean values of the importance and satisfaction ratings (see Azzopardi and Nash, 2013: 226 for using data-centered crosshair points in IPA). Additionally, we include a diagonal line whose slope reflects an equal evaluation of importance and satisfaction. This extension of the quadrant method has been used in several studies to separate regions of different priorities (Sampson and Showalter, 1999; Slack, 1994; Weber, 2000).

Figures 3 and 4 provide the results of the IPAs for domestic and international tourists. As already indicated in Table 4, we generally observe a positive relationship between the importance and satisfaction ratings of the hospitality core dimensions. For domestic tourists, most dimensions are either located in the first ("Keep up the good work") or the third ("Low priority") quadrants of the IPA grid, suggesting that the lower hospitality satisfaction of domestic tourists is mainly driven by dimensions which they also consider of less importance (see Figure 3). The area above the "iso-priority" diagonal of the IPA grid shows that the performance-importance discrepancies are largest for service providers' service and professional expertise and cordiality. A more positive perception of commercial hospitality by domestic tourists may be achieved if touristic service providers improve in these areas.

With regard to international tourists, the IPA in Figure 4 suggests that touristic service providers should mainly focus on the dimensions of service and professional expertise and interest and openness, which are located in the fourth quadrant of the IPA grid, to improve the hospitality perceptions of their international guests. Investments in these areas also seem to be crucial when considering the "iso-priority" diagonal. In contrast, international and domestic tourists are already highly satisfied with touristic service providers' helpfulness, appreciation and respect, and reliability. These hospitality core dimensions are important for keeping a positive perception of commercial hospitality for international as well as domestic guests traveling in Switzerland. 


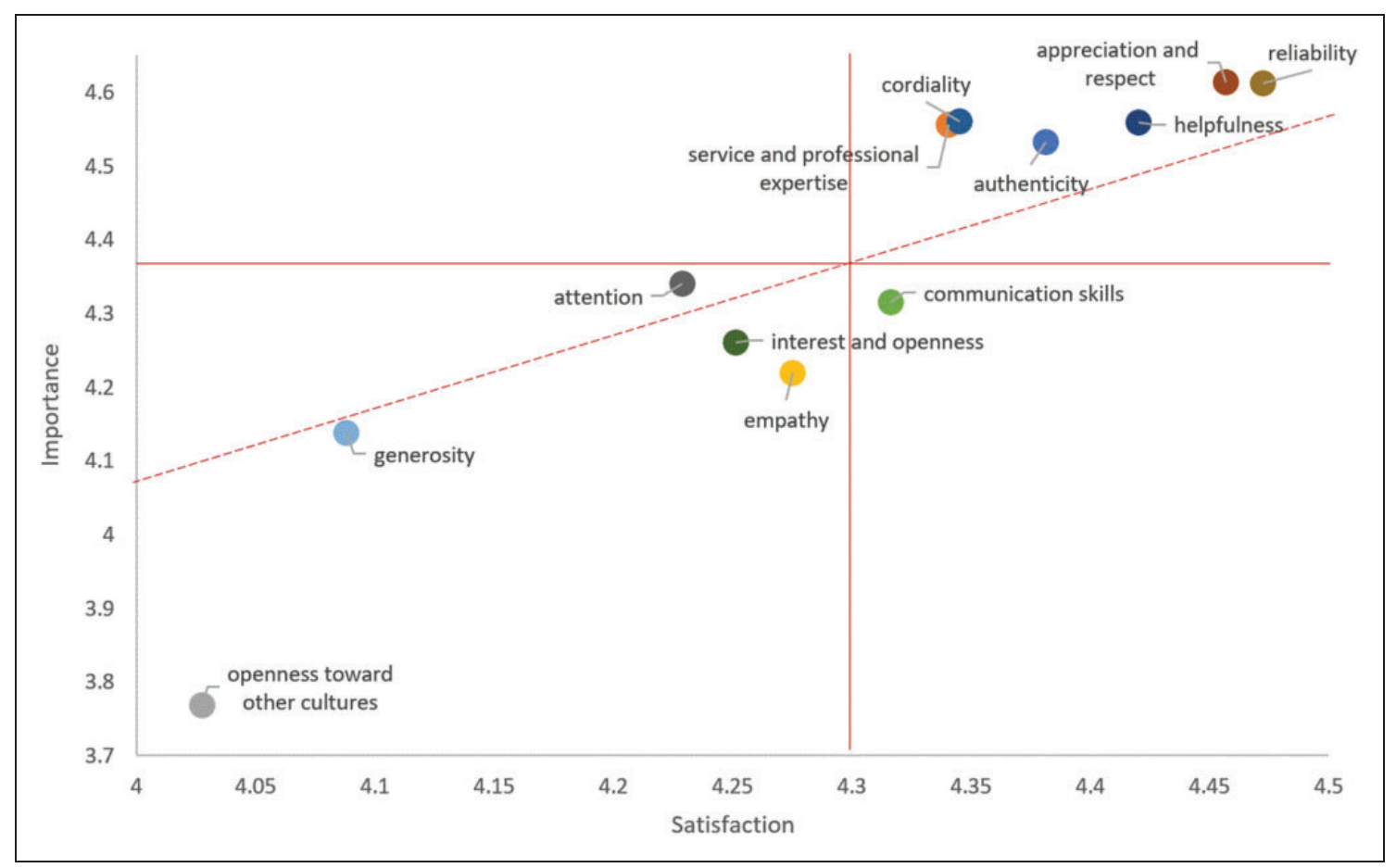

Figure 3. Hospitality importance-performance analysis for domestic tourists.

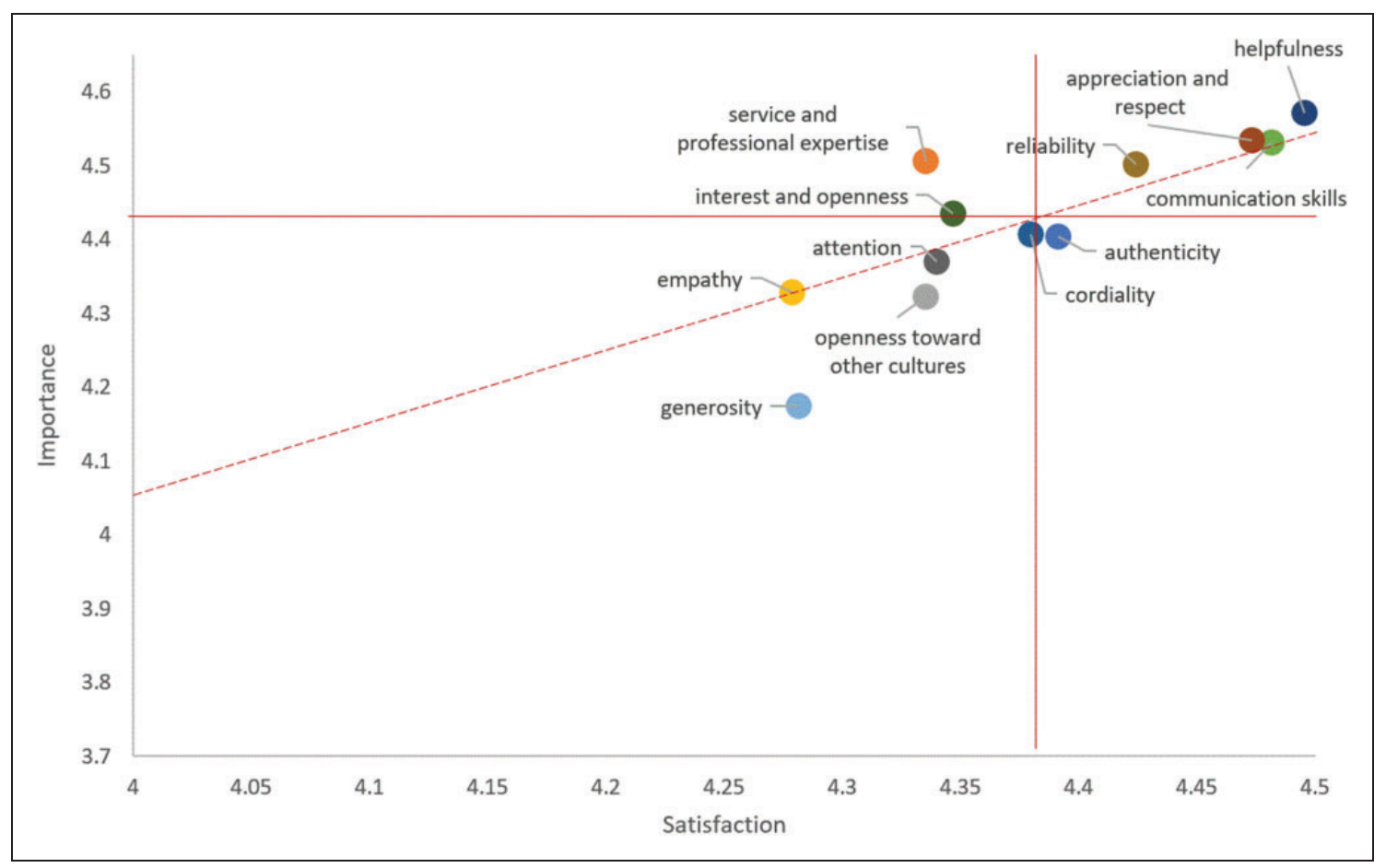

Figure 4. Hospitality importance-performance analysis for international tourists. 


\section{Discussion}

\section{Theoretical contribution}

This study is a first attempt to differentiate the influence of tourist-related characteristics on hospitality perceptions in a commercial tourism context. Given the lack of empirical attention to this line of inquiry, the character of this research is still exploratory. Yet, the analyses provide first insights into the perceptions of commercial hospitality of domestic and international tourists and point at potential improvements for touristic service providers in Switzerland. We find that domestic and international tourists traveling in Switzerland place similar importance on commercial hospitality but domestic tourists are significantly less satisfied with their hospitality experiences in touristic service encounters. Importantly, this holds true when controlling for several tourist-related characteristics that may influence their hospitality perceptions, including gender, age, level of education, type of accommodation, and the size of their place of residence. In line with previous studies of tourists' origin and related service expectations (Ariffin and Maghzi, 2012; Weiermair, 2000), we explain this finding by the fact that international tourists do not have a specific standard by which to evaluate their hospitality experience. International tourists therefore tend to be more tolerant and less critical toward the service qualities associated with hospitality. The regression analyses further indicate that the importance and satisfaction ratings of commercial hospitality are related to other demographic characteristics. Older tourists and female travelers give significantly more weight to hospitality in touristic service encounters than do younger tourists and males. While older tourists are also more satisfied with their hospitality experiences than younger ones, females are significantly less satisfied than males. This is in line with earlier work supporting the influence of tourists' gender on their expectations toward and satisfaction with service quality (Ariffin and Maghzi, 2012; Suki, 2014). Previous evidence also confirms that older people place higher importance upon several service quality dimensions (Webster, 1989).

The deeper analysis of individual hospitality core dimensions reveals further differences in the hospitality perceptions of domestic and international tourists in Switzerland. In line with our hypothesis, domestic and international tourists seem to have different expectations and satisfaction ratings across the individual dimensions of the hospitality concept, with the largest differences in service providers' openness toward other cultures. However, domestic and international tourists generally evaluate important dimensions more favorably than less-important dimensions. This finding is consistent with earlier IPAs in the tourism context, suggesting a positive relationship between the importance and performance ratings of service attributes in different settings (Hollenhorst et al., 1992; Oh, 2001). Key areas of improvement for domestic tourists are service providers' service and professional expertise and cordiality. For international tourists, key areas of action are service providers' service and professional expertise and interest and openness toward their guests.

By further developing the scale of commercial hospitality of Stettler et al. (2020), this study also contributes to the operationalization of the hospitality construct. The modified 12-item scale used to measure hospitality importance and hospitality satisfaction is similar to the 10-item hospitableness scale of Tasci and Semrad (2016). While the measurement instrument needs to be further validated (see Section Limitations and future research), the relationships between tourists' characteristics and hospitality perceptions presented here are robust toward different specifications of the hospitality scale and in different regression models.

\section{Managerial implications}

Touristic service providers with a large share of domestic guests should be aware that domestic tourists may have a more demanding and critical perception of hospitality in touristic service encounters, as illustrated in the case of Switzerland. In Switzerland, the differences in hospitality perceptions are mainly driven by domestic tourists' low evaluation of service providers' openness toward other cultures and their generosity. To derive strategic areas of improvement, it is, however, crucial to consider tourists' perceived importance of the individual dimensions of the hospitality concept. The joint consideration of the importance and satisfaction ratings indicates that touristic service providers in Switzerland should mainly invest in service and professional expertise, for example, by ensuring the competent answering of customers' questions. This is a key area of action to improve the hospitality perceptions of both domestic and international tourists traveling in Switzerland. Touristic service providers may also express more cordiality, for example, by showing more positive emotions and sympathy toward domestic guests and becoming more open-minded toward international guests in order to enhance their hospitality perceptions.

Overall, our findings highlight that the specific characteristics of a touristic target group influence their expectations and perceptions of hospitality in touristic service encounters. This requires that 
touristic service providers know the composition and the needs of their guests in the first place to then derive effective strategies, considering the importance of the different service dimensions that are associated with hospitality.

\section{Limitations and future research}

The main limitations of this study involve the measurement instrument. As already noted in the existing literature, the concept of hospitality is difficult to measure because of the intangibility of emotionally laden constructs and the influence of cultural, personal, and situational factors on hospitality experiences (Pijls et al., 2017; Tasci and Semrad, 2016). Limitations on the use of such scales are that the perception of hospitality is specific to time and place (Telfer, 2001) and people unavoidably have to think explicitly about aspects of service delivery that they normally process unconsciously. Furthermore, even if the wording is carefully chosen and tested, the formulation of the questions may influence the outcome. We can therefore not completely rule out a language effect on the answers of domestic tourists (German questionnaire) and international tourists (English questionnaire), despite multiple consistency checks.

The biggest shortcoming of this paper is that the scale of commercial hospitality of Stettler et al. (2020) used in this study had not been quantitatively validated in previous research. We tried to address this limitation post-hoc using CFA, principal component analyses, and reliability tests. The modified hospitality importance and satisfaction scales appear to be unidimensional and meet the model fit criteria of the CFA. Yet, the scale purification procedure did not include an exploratory analysis of the factor structure and step-by-step reduction of a large item pool in multiple quantitative studies with different samples. The operationalization of the hospitality core dimensions, their underlying relationships, and the one-dimensional structure of the hospitality construct, at this stage, need to be further validated in future research. In view of this limitation, it is important to test the robustness of the present results using other hospitality scales that have emerged in recent literature (e.g., Mody et al., 2019; Pijls et al., 2017; Tasci and Semrad, 2016 ). Upcoming studies on tourists' hospitality perceptions may, for example, go beyond the experiences of employee behavior and incorporate experiences of the tangible service environment as part of commercial hospitality (see Pijls et al., 2017: 125). Finally, considering the importance of overseas tourists from Asia or America for the Swiss tourism industry (Swiss Tourism Federation, 2019), the impact of different cultural backgrounds on hospitality perceptions should be addressed in more detail in future research. Forthcoming studies may also extend the analysis of hospitality perceptions in terms of tourist-related characteristics and consider more behavioral variables, such as tourists' travel experience, travel mode, or travel purpose. Including additional characteristics that may affect tourists' expectations and perceptions of commercial hospitality would be beneficial to validate and extend the present results. Overall, the further pinpointing of service improvements to enhance the hospitality perceptions of different tourist segments would be valuable for both tourism researchers and practitioners.

\section{Acknowledgments}

We gratefully acknowledge the cooperation and support of all practice partners who assisted with this survey. Special thanks also go to Barbara Rosenberg, Oliva Amstad, and Esther Galliker from the Lucerne School of Business, and to Beatrice Durrer from the Lucerne School of Social Work for their valuable contributions.

\section{Declaration of Conflicting Interests}

The author(s) declared no potential conflicts of interest with respect to the research, authorship, and/or publication of this article.

\section{Funding}

The author(s) disclosed receipt of the following financial support for the research, authorship and/or publication of this article: This work was supported by Innosuisse-Swiss Innovation Agency (16617.1 PFES-ES).

\section{ORCID iD}

Angela Steffen (D) https://orcid.org/0000-0002-4029-5953

\section{Notes}

1. Two-sided t-tests of the hospitality importance and satisfaction ratings did reject significant differences between the tablet PC and paper-and-pencil forms.

2. In 2018 , Germany accounted for $18.2 \%$ of the total foreign demand for overnight stays in Swiss hotels, followed by the United States (10.5\%), the United Kingdom $(7.7 \%)$, and China (7.1\%). Altogether, foreign European tourists accounted for $57.3 \%$, Asian tourists for $25.3 \%$, and American tourists for $14.2 \%$ of the total overnight stays of international tourists (Swiss Tourism Federation, 2019).

3. Hu and Bentler (1999) suggest that improvements in the TLI greater than 0.02 are of substantive interest.

4. Our results remained robust when we investigated the relationship of tourists' characteristics and hospitality perceptions in a structural equation model in which we 
considered the error correlations between friendliness and service and professional expertise, as indicated by the modification indices. Results are available upon request.

5. We applied ordered logistic regression because the importance and satisfaction scales for the hospitality core dimensions were ordinal and could not be treated as metric (see Section Measurement scale). Ordinal regression models may be applied to continuous response variables and are particularly useful when the response variable is skewed, as in our case (Liu et al., 2017). The results do not change if we use standard regression analysis for interval data.

6. Note that this finding does not contradict the overall positive effect of hospitality importance on hospitality satisfaction mentioned above. Additional analyses show that female tourists who place higher importance on hospitality tend to be significantly more satisfied with their hospitality experiences than female tourists who rate hospitality as less important. However, for females, this positive relationship between hospitality importance and satisfaction is lower than for males.

\section{Supplemental material}

Supplemental material for this article is available online.

\section{References}

Ahmad MS, Ariffin AAM and Ahmad A (2008) Evaluating the services of Malaysian hotels from the leisure traveler's perspectives. Furnal pengurusan (UKM fournal of Management) 27: 69-83.

Ariffin AAM and Maghzi A (2012) A preliminary study on customer expectations of hotel hospitality. International Fournal of Hospitality Management 31(1): 191-198.

Ariffin AAM, Maghzi A and Aziz NA (2011) Understanding hotel hospitality and differences between local and foreign guests. International Review of Business Research Papers 7(1): 340-349.

Asendorpf JB (2011) Persönlichkeitspsychologie [Personality Psychology]. Berlin, Heidelberg: Springer.

Azzopardi E and Nash R (2013) A critical evaluation of importance-performance analysis. Tourism Management 35: 222-233.

Babbie ER (2013) The Practice of Social Research. Belmont, CA: Wadsworth Cengage Learning.

Bishop Gagliano K and Hathcote J (1994) Customer expectations and perceptions of service quality in retail apparel specialty stores. Fournal of Services Marketing 8(1): 60-69.

Blain M and Lashley C (2014) Hospitableness. Research in Hospitality Management 4(1-2): 1-8.

Bohnsack R (2014) Rekonstruktive Sozialforschung: Einführung in Qualitative Methoden. Opladen, Toronto: Budrich.

Brotherton B (1999) Towards a definitive view of the nature of hospitality and hospitality management. International Fournal of Contemporary Hospitality Management 11(4): 165-173.

Brotherton B (2005) The nature of hospitality. Tourism and Hospitality Planning E Development 2(3): 139-153.
Brotherton B and Wood RC (2008) The nature and meanings of 'hospitality'. In: Wood RC and Brotherton B (eds) The SAGE Handbook of Hospitality Management. London: SAGE Publications, pp. 36-61.

Burgess J (1982) Perspectives on gift exchange and hospitable behaviour. International fournal of Hospitality Management 1(1): 49-57.

Callan RJ and Bowman L (2000) Selecting a hotel and determining salient quality attributes: A preliminary study of mature British travellers. International fournal of Tourism Research 2(2): 97-118.

Churchill GA (1979) A paradigm for developing better measures of marketing constructs. Fournal of Marketing Research 16(1): 64-73.

Clark LA and Watson D (1995) Constructing validity: Basic issues in objective scale development. Psychological Assessment 7(3): 309-319.

Cristobal E, Flavián C and Guinalíu M (2007) Perceived eservice quality (PeSQ). Managing Service Quality: An International fournal 17(3): 317-340.

Deppermann A (2000) Ethnographische Gesprächsanalyse: $\mathrm{Zu}$ Nutzen und Notwendigkeit von Ethnographie für die Konversationsanalyse. Online-Zeitschrift zur verbalen Interaktion (1): 96-124.

Deppermann A (2008) Gespräche analysieren: Eine Einführung. Wiesbaden: VS Verlag für Sozialwissschaften.

Donthu N and Yoo B (1998) Cultural influences on service quality expectations. Fournal of Service Research 1(2): 178-186.

Duden (n.d.) Herzlichkeit [Cordiality]. Available at: www. duden.de/rechtschreibung/Herzlichkeit (accessed 9 August 2019).

Flanagan JC (1954) The critical incident technique. Psychological Bulletin 51(4): 327-358.

Gremler DD (2004) The critical incident technique in service research. Fournal of Service Research 7(1): 65-89.

Hemmington N (2007) From service to experience. The Service Industries fournal 27(6): 747-755.

Hockling S (2013) Wenn die Korpersprache den Chef verrät [When body language gives the boss away]. Available at: www.zeit.de/karriere/beruf/2013-09/chefsache-koerper sprache-fuehrungskraefte (accessed 9 August 2019).

Hollenhorst SJ, Olson D and Fortney R (1992) Use of importance-performance analysis to evaluate state park cabins: the case of the West Virginia state park system. Fournal of Park and Recreation Administration 10(1): 1-11.

Hu L-t and Bentler PM (1999) Cutoff criteria for fit indexes in covariance structure analysis: Conventional criteria versus new alternatives. Structural Equation Modeling: $A$ Multidisciplinary fournal 6(1): 1-55.

Hudson S and Shephard G (1998) Measuring service quality at tourist destinations. Fournal of Travel $\mathcal{E}$ Tourism Marketing 7(3): 61-77.

Iacobucci D and Ostrom A (1993) Gender differences in the impact of core and relational aspects of services on the evaluation of service encounters. Fournal of Consumer Psychology 2(3): 257-286.

Joppe M, Martin DW and Waalen J (2001) Toronto's image as a destination. Fournal of Travel Research 39(3): 252-260. 
Juwaheer TD (2007) Using service quality expectations as a criterion to segment international tourists in the hospitality industry. Fournal of Travel E Tourism Marketing 21(23): $1-18$.

Kim S and Stoel L (2004) Apparel retailers: Website quality dimensions and satisfaction. Fournal of Retailing and Consumer Services 11(2): 109-117.

King CA (1995) What is hospitality? International fournal of Hospitality Management 14(3-4): 219-234.

Koll O, Wallpach S and von Kreuzer M (2010) Multimethod research on consumer-brand associations: Comparing free associations, storytelling, and collages. Psychology \& Marketing 27(6): 584-602.

Kreß F, Angermann J, Bauer A et al. (2018) "Keep up the good work"? In: Bieger T, Beritelli P and Laesser C (eds) Schweizer fahrbuch für Tourismus 2017/2018. Berlin: Erich Schmidt, pp. 45-60.

Lashley C (2001) Towards a theoretical understanding. In: Lashley C and Morrison A (eds) In Search of Hospitality: Theoretical Perspectives and Debates. Stoneham, MA: Butterworth-Heinemann, pp. 1-17.

Lashley C (2008) Studying hospitality. Scandinavian fournal of Hospitality and Tourism 8(1): 69-84.

Lashley C (2015) Hospitality and hospitableness. Research in Hospitality Management 5(1): 1-7.

Liu Q, Shepherd BE, Li C, et al. (2017) Modeling continuous response variables using ordinal regression. Statistics in Medicine 36(27): 4316-4335.

Lynch P, Molz JG, Mcintosh A, et al. (2011) Theorizing hospitality. Hospitality E Society 1(1): 3-24.

Marsh HW, Hau K-T and Wen Z (2004) In search of golden rules: Comment on hypothesis-testing approaches to setting cutoff values for fit indexes and dangers in overgeneralizing $\mathrm{Hu}$ and Bentler's (1999) findings. Structural Equation Modeling: A Multidisciplinary fournal 11(3): 320-341.

Martilla JA and James JC (1977) Importance-performance analysis. Fournal of Marketing 41(1): 77-79.

Matsunaga M (2010) How to factor-analyze your data right: do's, don'ts, and how-to's. International fournal of Psychological Research 3(1): 97-110.

Mattila AS (1999) The role of culture in the service evaluation process. Fournal of Service Research 1(3): 250-261.

Mattila AS, Grandey AA and Fisk GM (2003) The interplay of gender and affective tone in service encounter satisfaction. Fournal of Service Research 6(2): 136-143.

McCullagh P (1980) Regression models for ordinal data. fournal of the Royal Statistical Society: Series $B$ (Methodological) 42(2): 109-142.

Mody M, Suess C and Lehto X (2019) Going back to its roots: Can hospitableness provide hotels competitive advantage over the sharing economy? International Fournal of Hospitality Management 76: 286-298.

Müller H and Boess M (1995) Tourismusbewusstsein: Empirische Belege und Hintergründe. Forschungsinstitut für Freizeit und Tourismus [Tourism consciousness: Empirical evidence and backgrounds]. Forschungsinstitut für Freizeit und Tourismus der Universität Bern (ed), Bern.
Murad H, Fleischman A, Sadetzki S, et al. (2003) Small samples and ordered logistic regression. The American Statistician 57(3): 155-160.

Nameghi ENM and Ariffin AAM (2013) The measurement scale for airline hospitality. Fournal of Air Transport Management 30: 1-9.

Nunnally JC and Bernstein IH (2008) Psychometric Theory. New York, NY: McGraw-Hill.

Oh H (2001) Revisiting importance-performance analysis. Tourism Management 22(6): 617-627.

Ottenbacher M, Harrington R and Parsa HG (2009) Defining the hospitality discipline. Fournal of Hospitality E Tourism Research 33(3): 263-283.

Parasuraman A, Zeithaml V and Berry LL (1988) SERVQUAL: A multiple-item scale for measuring consumer perceptions of service quality. Fournal of Retailing 64(1): 12-40.

Pechlaner H and Raich F (2007) Gastfreundschaft und Gastlichkeit im Tourismus [Hospitality and hospitableness in tourism: customer satisfaction and loyalty with hospitality management]. Berlin: Erich Schmidt.

Pechlaner H, Volgger M and Nordhorn C (2017) Hospitality management ist mehr als service management [Hospitality management is more than service management]. In: Pechlaner $\mathrm{H}$ and Volgger $\mathrm{M}$ (eds) Die Gesellschaft auf Reisen - Eine Reise in die Gesellschaft [Society on the Move - a fourney into Society]. Wiesbaden: Springer VS, pp. 139-161.

Perathoner G (2000) Gastfreundschaft im Tourismus: Eine Tugendethik aus der Sicht des Gastgebers [Hospitality in Tourism: Virtue Ethics from the Point of View of the Host]. Münster: LIT Verlag.

Pfeifer Y (1983) Small business management. In: Cassee E (ed.) The Management of Hospitality. Oxford: Pergamon Press, pp. 189-202.

Pijls R, Groen BH, Galetzka M, et al. (2017) Measuring the experience of hospitality. International fournal of Hospitality Management 67: 125-133.

Pizam A and Shani A (2009) The nature of the hospitality industry. Anatolia 20(1): 134-150.

Pizam A and Sussmann S (1995) Does nationality affect tourist behavior? Annals of Tourism Research 22(4): 901-917.

Reid RD and Bojanic DC (2010) Hospitality Marketing Management. Hoboken, NJ: Wiley.

Reisinger Y and Turner LW (2003) Cross Cultural Behaviour in Tourism: Concepts and Analysis. Oxford: Butterworth Heinemann.

Ritzer G (2007) Inhospitable hospitality?. In: Lashley C, Lynch P and Morrison A (eds) Hospitality Oxford: Elsevier, pp. 129-139.

Romeiss-Stracke F (1995) Servicequalität im Tourismus [Service quality in tourism]. Report, Allg. Deutscher Automobil-Club ADAC (ed), München.

Saleh F and Ryan C (1992) Client perceptions of hotels. Tourism Management 13(2): 163-168.

Sampson SE and Showalter MJ (1999) The performanceimportance response function. The Service Industries fournal 19(3): 1-25. 
Sánchez-Hernández RM, Martínez-Tur V, Peiró JM, et al. (2010) Linking functional and relational service quality to customer satisfaction and loyalty: Differences between men and women. Psychological Reports 106(2): 598-610.

Sim J, Mak B and Jones D (2006) A model of customer satisfaction and retention for hotels. Fournal of Quality Assurance in Hospitality \& Tourism 7(3): 1-23.

Skandrani H and Kamoun M (2014) Hospitality meanings and consequences among hotels employees and guests. In: Woodside AG and Kozak M (eds) Tourists' Perceptions and Assessments. Bingley, U.K: Emerald, pp. 147-156.

Slack N (1994) The importance-performance matrix as a determinant of improvement priority. International Fournal of Operations \& Production Management 14(5): 59-75.

Smith SLJ (1994) The tourism product. Annals of Tourism Research 21(3): 582-595.

Stettler J, Amstad O, Roserberg-Taufer B, et al. (2020) Understanding hospitality. ITW Working Paper Series 2020(forthcoming).

Suki NM (2014) Moderating role of gender in the relationship between hotel service quality dimensions and tourist satisfaction. Fournal of Quality Assurance in Hospitality $\mathcal{E}$ Tourism 15(1): 44-62.

Swiss Tourism Federation (2019) Swiss tourism in figures 2018: Structure and industry data. Report, Bern. Available at: www.stv-fst.ch/stiz (accessed 14 July 2020).

Tabassum A, Rahman T and Jahan K (2012) Assessment of service quality in tourist hotels of cox's bazaar in terms of demographic characteristics of tourists. World Fournal of Social Science 2(4): 44-64.

Tajeddini K (2010) Effect of customer orientation and entrepreneurial orientation on innovativeness: evidence from the hotel industry in Switzerland. Tourism Management 31(2): 221-231.

Tasci ADA and Semrad KJ (2016) Developing a scale of hospitableness. International fournal of Hospitality Management 53: 30-41.

Telfer E (2001) The philosophy of hospitableness. In: Lashley C and Morrison A (eds) In Search of Hospitality: Theoretical Perspectives and Debates. Stoneham, MA: Butterworth-Heinemann, pp. 38-55.

Teng C-C (2011) Commercial hospitality in restaurants and tourist accommodation: Perspectives from international consumer experience in Scotland. International fournal of Hospitality Management 30(4): 866-874.

Thiem M (1996) Tourismus und kulturelle Identität: Die Bedeutung des Tourismus für die Kultur touristischer Zielund Quellgebiete [Tourism and Cultural Identity: The Meaning of Tourism for the Culture of Touristic Destinations and Source Regions]. Forschungsinstitut für Freizeit und Tourismus der Universität Bern (ed), Bern.

Tideman MC (1983) External influences on the hospitality industry. In: Cassee $\mathrm{E}$ (ed.) The Management of Hospitality. Oxford: Pergamon Press, pp. 1-23.
Torres EN, Fu X and Lehto X (2014) Examining key drivers of customer delight in a hotel experience. International Fournal of Hospitality Management 36: 255-262.

Tsaur S-H, Lin C-T and Wu C-S (2005) Cultural differences of service quality and behavioral intention in tourist hotels. Fournal of Hospitality $\mathcal{E}$ Leisure Marketing 13(1): 41-63.

Weber K (2000) Meeting planners' perceptions of hotelchain practices and benefits. Cornell Hotel and Restaurant Administration Quarterly 41(4): 32-38.

Webster C (1989) Can consumers be segmented on the basis of their service quality expectations? fournal of Services Marketing 3(2): 35-53.

Weiermair K (2000) Tourists' perceptions towards and satisfaction with service quality in the cross-cultural service encounter. Managing Service Quality: An International fournal 10(6): 397-409.

Weiermair K and Fuchs M (1999) Measuring tourist judgment on service quality. Annals of Tourism Research 26(4): 1004-1021.

World (2018) Travel \& Tourism Council Domestic tourism: Importance and economic impact. Report, London, December 2018. Available at: www.wttc.org/ publications.

Yuksel A (2004) Shopping experience evaluation: a case of domestic and international visitors. Tourism Management 25(6): 751-759.

Zeithaml VA, Berry LL and Parasuraman A (1993) The nature and determinants of customer expectations of service. Fournal of the Academy of Marketing Science 21(1): $1-12$.

\section{Author Biographies}

Angela Steffen is Senior Research Associate at the Lucerne School of Business. She received her PhD in Behavioral Economics from the University of Bern, Switzerland. Her research interests focus on consumer perceptions, behavioral pricing, and field experiments in tourism.

Jürg Stettler heads the Institute of Tourism at the Lucerne School of Business, Switzerland. He is also deputy director and head of the Research department. His core competencies in teaching, research, and consulting projects are in the fields of destination management, sustainable development in tourism, and event impact analyses.

Lukas Huck, MA, is a Research Associate at the Institute of Tourism at the Lucerne School of Business, Switzerland. His consultancy and research work focuses on destination management and sustainable tourism development. 